fracture tend to be younger and have more chronic diseases at the time of their fracture. Fractures may be markers for underlying frailty and account for the almost doubling of risk for mortality among men after a hip fracture compared with women in other studies. ${ }^{7,8}$ Another potential explanation for the increased risk could be the low rate of investigation for bone disease in men after fracture. ${ }^{9}$

Cognitive impairment and dementia are major risk factors for fall-related fractures. Patients with these conditions are generally under-represented in cohort studies because of the challenge of recruiting them. If that was the case in this Canadian cohort (and it most likely was), the mortality data may contain "healthy volunteer bias" and the population mortality rates may be even higher than reported by Ioannidis and colleagues. Along these lines, the average age of patients with a hip fracture in this study was 71 , while the average age of Canadians with hip fracture is a decade later. We question whether a registry of hip fractures in Canada might find annual mortality rates that are even higher than those reported here.

Despite the clearly catastrophic nature of osteoporotic hip and vertebral fractures, patients often do not receive optimal care. In a small randomized controlled trial to improve community-based care after hip fracture,$^{10}$ we noted that less than one-third of patients in the control group received care (bone mineral density assessment, bisphosphonates, vitamin $\mathrm{D}$, calcium or exercise prescription) despite being admitted to a major tertiary facility and having follow-up by a family physician. What systems, resources and strategy are being devoted to a condition that kills at least one-quarter of its victims within 12 months? There is room for improvement.
This article has been peer reviewed.

Competing interests: None declared.

\section{REFERENCES}

1. Ioannidis G, Papaioannou A, Hopman WM, et al. Relation between fractures and mortality: results from the Canadian Multicentre Osteoporosis Study. CMAJ 2009. DOI: $10.1503 / \mathrm{cmaj} .081720$

2. Lyles KW, Colon-Emeric CS, Magaziner JS, et al. Zoledronic acid in reducing clinical fracture and mortality after hip fracture. New Engl J Med 2007;357: nihpa40967.

3. Jarvinen TL, Sievanen H, Khan KM, et al. Shifting the focus in fracture prevention from osteoporosis to falls. BMJ 2008;336:124-6.

4. Gillespie LD, Robertson MC, Gillespie WJ, et al. Interventions for preventing falls in older people living in the community. Cochrane Database Syst Rev 2009. 15;(2):CD007146.

5. Kannus P, Parkkari J, Niemi S, et al. Prevention of hip fracture in elderly people with use of a hip protector. N Engl J Med 2000;343:1506-13

6. Majumdar SR, Beaupre LA, Harley $\mathrm{CH}$, et al. Use of a case manager to improve osteoporosis treatment after hip fracture: results of a randomized controlled trial. Arch Intern Med 2007:167:2110-5.

7. Abrahamsen B, van Staa T, Ariely R, et al. Excess mortality following hip fracture: a systematic epidemiological review. Osteoporos Int DOI:10.1007/s00198-0090920-3. Epub 2009 May 7 ahead of print.

8. Bliuc D, Nguyen ND, Milch VE et al. Mortality risk associated with low-trauma osteoporotic fracture and subsequent fracture in men and women. JAMA 2009; 301:513-21

9. Feldstein AC, Nichols G, Orwoll E, et al. The near absence of osteoporosis treatment in older men with fractures. Osteoporos Int 2005;16:953-62.

10. Davis JC, Guy P, Ashe MC, et al. HipWatch: osteoporosis investigation and treatment after a hip fracture: a 6-month randomized controlled trial. J Gerentol A Biol Sci Med Sci 2007;62:888-91.

Correspondence to: Dr. Karim M. Khan, Centre for Hip Health and Mobility, Vancouver General Hospital, Department of Family Practice, University of British Columbia, 303-2647 Willow St., Vancouver BCV5Z1M9; karim.khan@ubc.ca

\title{
Using education to improve control of asthma in children
}

\section{Christopher Cates BM BCh}

Previously published at www.cmaj.ca on Aug. 17, 2009.

$\mathrm{E}$ ducational interventions can be helpful for the management of asthma in children for whom medical treatment has failed to prevent exacerbations. ${ }^{1}$ The optimal duration, type and intensity of educational interventions, however, remains unclear.

In this issue of CMAJ, Watson and colleagues ${ }^{2}$ present their findings from a prospective, randomized controlled trial in which they evaluated the impact of asthma-related education provided in a small-group, interactive format to children with asthma and their families. The authors observed a significant reduction in visits to the emergency department during the year after the educational program among children in the intervention group. Their results are

\section{Key points}

- Educational interventions for children with asthma and their families may reduce visits to the emergency department and admissions to hospital.

- A small-group educational format may help improve control of asthma by giving families the opportunity to air and address their individual concerns.

Christopher Cates is with the Department of Community Health Sciences, St George's University of London, London, UK.

Cite as CMAJ 2009. DOI:10.1503/cmaj.091120 
consistent with those of a recently updated Cochrane systematic review. ${ }^{1}$

Taken in isolation, the study by Watson and colleagues has some limitations. The trial aimed to recruit children aged 3-16 years and used a different educational approach for each of 3 age groups (i.e., 3-6 years, 7-11 years and 12-16 years). A breakdown of the results by age group and the mean age of the participants ( 7.4 years with a standard deviation of 3.4 years) suggests that few adolescents were enrolled. From the results presented, therefore, we cannot draw conclusions for adolescents about the impact of the educational intervention. This age group is particularly challenging to engage. But evidence of benefit to adolescents of educational intervention exists, as reported by authors who evaluated a peer-led program in Australia. ${ }^{3}$

The study by Watson and colleagues was also limited by a low rate of recruitment. Only 398 families were enrolled out of 2901 who appeared eligible from emergency departmental records. The families who responded to invitations to participate in this study likely had higher levels of motivation than the nonresponders. This probable difference suggests that the results of the study can be applied to families who respond positively to offers of support and education. But we cannot assume that the small-group format would work equally well with families who are less motivated.

Finally, the number of admissions to hospital among participants was too small to assess in this study. Nevertheless, a significant reduction was observed in the number of courses of oral corticosteroids used per child after the group-oriented educational intervention involving the families of these children. This reduction suggests that the intervention did not just reduce visits to the emergency department by catching exacerbations of asthma earlier with oral corticosteroids, but that it improved control of asthma to a level at which fewer exacerbations were taking place.

Despite the limitations of the study by Watson and colleagues, their results are consistent with those of other trials. The recent Cochrane review of studies on this topic examined 38 trials that involved 7843 children and included a wide variety of educational interventions. ${ }^{1}$ Variation existed across these studies in the type and intensity of intervention used, the professional orientation of personnel delivering the education (who included nurses, trained health educators, social workers and a case manager), the duration of the intervention and follow-up, and the intensity of the control-group intervention. It was not possible to identify differences in the impact of education by examining prespecified subgroups. The most important aspects of educational intervention, therefore, cannot be identified from the available evidence. But the increased power of a review, because it involves a large number of patients, suggests that educational interventions reduce both hospital admissions and visits to the emergency department. Overall, the review found a reduction of one quarter in visits to the emergency department and a similarly significant relative reduction in hospital admissions.

At a fundamental level, we need to determine why individual families take their children to the emergency department and the key factors involved for each of them when exacerba- tions of asthma occur. We know that many children with asthma stop using their preventer inhalers. ${ }^{4}$ But our approach has shifted away from blaming families for failures involving the use of medication to one of sharing responsibility for and understanding of individual issues. ${ }^{5}$

What matters to children and their families is not so much the general theory behind asthma, but rather how asthma affects them. If we are to empower families to prevent visits to the emergency department by improving control of their children's asthma, we need to provide an environment where they can share their stories and air concerns. As doctors, we have a tendency to assume that we know what parents want for their children, and we are often wrong! ${ }^{6}$

In a study examining the impact of an intervention aimed at improving the prescribing of antibiotics for children with ear infections, we faced many of the same challenges faced by those who provide care to families of children with asthma. ${ }^{7,8}$ Contrary to our expectations, asking parents for their input revealed that many did not actually want an antibiotic for their child. The small-group approach for children with asthma may have been effective because it allowed families to share their own concerns and expectations.

We are unable to determine whether it matters who facilitates group-oriented education for such families or whether similar benefit could be obtained using community-based follow-up. These are suitable areas for further research. Nevertheless, the findings of Watson and colleagues suggest that families of children with asthma who visit emergency departments could benefit from the offer of supportive, group-oriented education. The supplementary materials that accompany these findings are welcome as they allow readers to see exactly what was done in the trial and adopt a similar approach. ${ }^{9}$

Competing interests: None declared.vvvvvrrr

\section{REFERENCES}

1. Boyd M, Lasserson TJ, McKean MC, et al. Interventions for educating children who are at risk of asthma-related emergency department attendance [review] Cochrane Database Syst Rev 2009(2):CD001290.

2. Watson WTA, Gillespie C, Thomas N, et al. Small-group, interactive education and the effect on asthma control by children and their families. CMAJ 2009. DOI:10.1503/cmaj.080947.

3. Shah S, Peat JK, Mazurski EJ, et al. Effect of peer led programme for asthma education in adolescents: cluster randomised controlled. BMJ 2001;322:583-5.

4. Cates C, Black P, Edsbacker S, et al. Comparison of inhaled beclomethasone and budesonide. BMJ 1999;319:124.

5. Mullen PD. Compliance becomes concordance. BMJ 1997;314:691.

6. Mangione-Smith R, McGlynn EA, Elliott MN, et al. The relationship between perceived parental expectations and pediatrician antimicrobial prescribing behavior Pediatrics 1999;103:711-8.

7. Cates CJ. Delayed antibiotics for children with acute otitis media: is practice change sustainable? Evid Based Med 2009;14:2-3.

8. Cates C. An evidence based approach to reducing antibiotic use in children with acute otitis media: controlled before and after study. BMJ 1999;318:715-6.

9. Glasziou P, Meats E, Heneghan C, et al. What is missing from descriptions of treatment in trials and reviews? BMJ 2008;336:1472-4.

Correspondence to: Dr. Christopher Cates, Department of Community Health Sciences, St. George's University of London, Cranmer Terrace, London SW12 ORE, UK; fax 0208725 3584; ccates@sgul.ac.uk 